\title{
SEGURANÇA NO TRABALHO: A PERCEPÇÃO DE ACADÊMICOS DE UM CURSO SUPERIOR DE TECNOLOGIA EM GESTÃO PÚBLICA
}

\author{
SAFETY AT WORK: THE PERCEPTION OF STUDENTS FROM A SUPERIOR \\ TECHNOLOGICAL COURSE ON PUBLIC MANAGEMENT
}

\author{
Paulo Eduardo Sobreira Moraes ${ }^{1}$ \\ João Antonio Palma Setti ${ }^{2}$
}

\section{Resumo}

O presente artigo contempla um estudo qualitativo acerca da percepção de acadêmicos de graduação em Curso Superior de Tecnologia em Gestão Pública, de uma instituição de Curitiba - PR, acerca das responsabilidades e misteres do gestor público quanto à Segurança no Trabalho. Os acadêmicos da unidade curricular "Segurança no Trabalho" se colocaram livremente assim como se dispuseram livremente a expressar suas percepções em entrevista não estruturada no ambiente de ensino-aprendizagem, tomaram parte na pesquisa duas turmas durante o ano de 2008. A responsabilidade trabalhista, civil e administrativa do gestor público acerca da segurança no trabalho emergiu como principal percepção entre os acadêmicos participantes da pesquisa.

Palavras-chave: Segurança no Trabalho; Gestão Pública; Educação Tecnológica.

\section{Abstract}

This article presents qualitative study on the perceptions of students from under-degree course in Superior Technological Education in Public Management, at an institution of Curitiba - PR,

\footnotetext{
${ }^{1}$ Doutor em Engenharia Florestal. Professor da Universidade Federal do Paraná e Pós-graduando em Engenharia de Segurança do Trabalho pela Pontifícia Universidade Católica do Paraná. Universidade Federal do Paraná Setor Escola Técnica da UFPR. Rua Dr. Alcides Vieira Arcoverde, 1225. Jardim das Américas. CEP: 81520260. Curitiba - Paraná - Brasil. Fone: (41) 3361-4900, pauloraes@ig.com.br ${ }^{2}$ Doutor em Engenharia Elétrica e Informática Industrial. Professor da Pontifícia Universidade Católica do Paraná da Universidade Tecnológica Federal do Paraná. Pontifícia Universidade Católica do Paraná. Rua Imaculada Conceição, 1155. Centro. CEPI: 80215-901. Curitiba - Paraná - Brasil. Fone: 3271-2661, j.setti@pucpr.br
} 
about the responsibilities of public managers and his imperatives about Safety at Work. The students of curriculum unit "Safety at Work" had free for exposed their own opinions like as were willing to freely express their perceptions in unstructured interviews in the teachinglearning environment, two classes during the year 2008 took part in this research. The responsibility at labor law, civil law and administrative law of the public manager about safety at work emerged as the main perception among the students participants in the research.

Keywords: Labor Safety; Public Management; Superior Technological Education. 


\section{Introdução}

A Segurança no Trabalho é dever do empregador e direito do empregado. Não obstante tal perspectiva seja mais comumente percebida no campo da iniciativa privada onde ações trabalhistas que contemplam o assunto são corriqueiras, também no setor público tal condição se verifica.

De fato, apoiando-se em Wachowicz (2007), a condição legal que obriga a segurança do trabalhador pelo empregador independe da condição pública, mista ou privada do mesmo.

A legislação afeta a área é vasta e fundamentalmente se baseia na Consolidação das Leis do Trabalho e em Normas Regulamentadoras, em concordância com Hoeppner (2007). Mas, há repercussões civis e penais além de previdenciárias quando do evento de acidentes do trabalho e de doenças decorrentes do mesmo.

Os gestores públicos podem ser chamados a responder civil e penalmente por acidentes do trabalho e por doenças dele decorrentes uma vez que se verifique a existência de nexo causal entre a doença ou acidente e seu proceder negligente, imprudente, imperito ou omisso.

O presente trabalho apresenta a percepção de acadêmicos do Curso Superior de Tecnologia em Gestão Pública quanto a tal realidade e alude à conscientização dos mesmos quanto às responsabilidades inerentes a posições gestoras na esfera do estado.

\section{Paradigma Científico e Metodologia de Pesquisa adotados}

Este trabalho assume o Paradigma Qualitativo como abalizamento científico para seus encaminhamentos. Em consonância com Moraes (2007), a opção por um paradigma científico reflete o viés do pesquisador no sentido em que este interpreta a realidade e reconstrói seu significado como conhecimento sistematizado e metodologizado de modo científico.

Ao se aderir a tal paradigma entende-se que o mesmo seja o mais adequado para o entendimento do objeto de estudo que é também qualitativo: a percepção de sujeitos sobre algo que lhes é peculiar ou que lhes concerne. Neste sentido, o modo como se dá o entendimento - no sentido de como se percebe - acerca do fato real "Segurança no Trabalho" por acadêmicos de um curso superior é algo eminentemente qualitativo. 


\section{DIVERS@!}

Assim, opta-se por discutir sob um ponto de vista que exclui generalizações e considerações quantitativas o que emerge com posicionamento eminentemente cognitivo enquanto acúmen do real - independentemente da consubstanciação de dados parametrizáveis ou passíveis de mensuração.

Por outro lado, se o paradigma é qualitativo, a metodologia adotada é a do estudo de caso; no sentido de que se faz um recorte sobre o universo e sobre este recorte se aplica o esforço de pesquisa.

Tal recorte constitui-se na integralidade dos alunos matriculados regularmente nos turnos matutino e noturno na unidade curricular "Segurança no Trabalho" durante o ano de 2008, integrante do Curso Superior de Tecnologia em Gestão Pública de uma faculdade voltada ao Ensino Tecnológico de Curitiba - Paraná, da qual um dos autores era professor no que o mesmo contou com o apoio de seus pares e superiores.

Tais acadêmicos foram convidados a se expressarem durantes as aulas e a participarem com suas opiniões acerca dos conteúdos ministrados durante as mesmas. Em especial sempre se convidou aos acadêmicos para apresentarem suas compreensões e percepções sobre a Segurança no trabalho como potenciais gestores públicos.

O universo dos participantes se constituiu de 17 (dezessete) acadêmicos, com idade variando entre 20 (vinte) e 50 (cinqüenta anos), distribuídos por gênero entre 15 (quinze) homens e 5 (cinco) mulheres. Todos atuando em organizações públicas, com exceção de uma pessoa desempregada.

Além disto, após as aulas aos alunos se convidou para expressarem-se acerca de tal condição em momento de entrevista não estruturada com o autor. Tais entrevistas não foram gravadas ou anotadas para que os alunos não se sentissem em absoluto constrangidos- 15 (quinze) expressaram que não gostariam que suas declarações fossem gravadas, pois que se sentiam desconfortáveis ao verem o gravador, ao passo que o autor registrava imediatamente ao final das mesmas as principais falas de cada aluno entrevistado. Assim, a não gravação das entrevistas se tornou o procedimento padrão.

Aos que se dispuseram a serem entrevistados se lhes assegurou o anonimato e a todos os alunos participantes da unidade curricular se lhes informou que o pesquisador utilizar-se-ia do que viviam em sala de aula como objeto de pesquisa, ao que não impuseram óbice.

Tais práticas se fundamentam no trabalho de autores que ou fazem uso do mesmo paradigma e método ou que tecem considerações específicas sobre metodologia; a saber: Franco (2008), Moraes (2007), Tiski (2006), Demo (2004), Moraes (2002), Franco (2001), 
Moser (2000), Moraes (2000), Godoy (1995), Gil (1994), Lakatos e Marconi (1991), Demo (1989), Richardson (1989) e Popper (1975).

A partir da fala dos acadêmicos e da recorrência das idéias, percepções e entendimentos que apresentaram traçou-se um conjunto de apontamento sobre a visão perceptiva que os mesmos têm acerca do objeto de estudo, do qual se passa a tratar mais acuradamente a seguir.

\section{Segurança no Trabalho}

A noção de Segurança no Trabalho nasce como resposta à condições de periculosidade e risco presentes nos locais ou inerentes às atividades peculiares ao processo laborativo. Isto é, se há insegurança para o empregado no contexto de sua atividade de trabalho então há que se dar condições de segurança no trabalho.

Assim, a eliminação do risco de acidente do trabalho e do advento da doença originada (parcial ou totalmente) pela atividade laboral constitui-se no escopo da Segurança do Trabalho. Proteger a integridade física, psicológica, social e moral do trabalhador - mantendo assim sua capacidade laboral - se enquadra nesta perspectiva. Neste sentido o treinamento de funcionários para que estes venham a ter uma atitude segura e prevencionista se enquadra em tal fito.

Se, todavia, vier a se dar o acidente é de demanda própria da Segurança do Trabalho mitigar os impactos do mesmo, gerindo a situação até que a regularização das condições se restaure e a prevenção a novos episódios negativos seja efetiva. Similarmente, ao trabalhador que sofreu dano a Segurança do Trabalho deve amparar desde os primeiros socorros até a sua possível reintegração às atividades laborais.

Cardella (1999) e Zocchio (2002), bem como Kawamoto (2002) e Gonçalves (2003), dão sustentação a tais perspectivas.

Mas, a Segurança do Trabalho também tem se constituído em uma estratégia institucional para seu desenvolvimento. Ao passo que o empregado é tratado com dignidade e vê que a instituição atua no sentido de sua proteção, então passa a desenvolver maior sentimento de pertença à instituição e adere mais facilmente a seus propósitos. Tal sentido de pertença e aderência de propósitos se traduz em efetividade produtiva e eficácia profissional. 
Moraes (2007, p.54) registra que "Sucesso organizacional é o estado em que se encontra uma instituição pública ou privada que atende aos quesitos mínimos de bom êxito em relação ao mercado ou área geográfica em que atua", e não há como atingir o sucesso se os colaboradores da instituição não se portarem de modo assertivo também em relação à segurança própria e à prevenção a acidentes.

A organização segura quanto aos misteres do trabalho, seja pública ou privada, não se encontra à mercê de eventuais episódios de acidentes que geram prejuízos vultosos. A organização que garante a saúde de seus colaboradores não tem porque temer os rigores da fiscalização trabalhista quanto ao cumprimento da legislação.

Certamente as instituições são obrigadas por força da legislação a manter um Sistema de Saúde e Segurança no Trabalho em função de suas dimensões e peculiaridades de constituição, conforme Araújo (2007) e também Hoeppner (2007).

Os concernidos, pois, à Segurança do trabalho são empregados e empregadores, cada qual segundo a finalidade de sua participação no ambiente de trabalho com as responsabilidades que lhes cabe. $\mathrm{O}$ empregador deve propiciar os meios pelos quais o trabalhador esteja seguro e não desenvolva doenças ocupacionais; assim como cabe ao trabalhador atender às diretrizes de segurança e seguir às orientações dos responsáveis técnicos e administrativos da área (inclusive fazendo uso de equipamentos coletivos e individuais de proteção, entre outras providências).

Quando uma das partes rompe com suas responsabilidades se cria a condição causal para acidentes do trabalho e doenças laborais que afetam a produtividade organizacional, causam prejuízos e danos a todos os concernidos - entre estes os familiares dos acometidos por doenças ou envolvidos em acidentes, o Estado, etc.

O gestor público, como todo gestor, deve estar atento a tal situação e tal condição que se passa a tratar a seguir.

\section{O Gestor Público e a Segurança no Trabalho}

Ao gestor público cabe a responsabilidade pela atividade de condução integral da instituição que participe do Estado (entendido como o conjunto da União, Unidades Federativas e Municípios e a reunião dos poderes: Executivo, Legislativo e Judiciário), serve à sociedade na consecução de seus objetivos e no prover de meios que a saciem. 


\section{DIVERS@!}

Como gestor da coisa pública está sujeito a legislações particulares de seu escopo de atuação, mas também à normas que são comuns à esfera privada de gestão. Em especial, a Norma Regulamentadora Número 1 é de interesse do gestor público e inicia-se como segue:

As Normas Regulamentadoras - NR, relativas à segurança e medicina do trabalho, são de observância obrigatória pelas empresas privadas e públicas e pelos órgãos públicos da administração direta e indireta, bem como pelos órgãos dos Poderes Legislativo e Judiciário, que possuam empregados regidos pela Consolidação das Leis do Trabalho - CLT (HOEPPNER, 2007).

Não obstante a referência explicita à CLT, é dever do gestor público também garantir ao empregado estatutário condições de segurança no trabalho do mesmo modo que ao enquadrado na CLT.

Então, ainda que o gestor público possa contar com a assessoria de profissionais técnicos, é dele a responsabilidade por cumprir e fazer cumprir os princípios legais e orientações da legislação no que tange à questão em foco. Até porque responderá em conjunto a sua assessoria técnica (técnico, tecnólogo ou engenheiro de segurança no trabalho; médico, enfermeiro, psicólogo ou fisioterapeuta do trabalho) por acidentes e danos ou doenças que o trabalhador venha a sofrer; mesmo que culpado in eligendo; culpa pela má escolha de profissionais que o assessoram.

No caso de comprovada a responsabilidade do gestor público por imperícia, imprudência, negligência ou omissão no advento de um acidente do trabalho ou doença laboral, ao Estado está reservado o direito de regresso se vier a ter perdas por ações judiciais trabalhistas e civis. Além disto, a responsabilidade penal é do gestor por morte, dano temporário ou permanente à saúde e integridade do trabalhador.

O Código Penal Brasileiro (Decreto-Lei N. ${ }^{\circ}$ 2.848, de 7 de Dezembro de 1940) inclusive reza em seu Artigo 32 que expor a vida ou a saúde de outrem a perigo direto e iminente pode levar a pena de detenção de três meses a um ano, se o fato não constitui crime mais grave. Assim, ao expor o trabalhador a risco desnecessário o gestor público poderá responder criminalmente por periclitação da vida.

A Segurança no Trabalho é tão importante para o Gestor Público como a responsabilidade administrativa, por exemplo. Com a diferença que incorrendo em crime administrativo o gestor público objetivamente não expõem alguém em particular à periclitação da vida. 
E sendo o objeto de preservação da Segurança do Trabalho a vida e a saúde do trabalhador, o Gestor Público deve se ater a princípios de ética e moral, pois que o servidor público é antes de tudo um servidor que pode responder por prevaricação - retardar ou deixar de praticar, indevidamente, ato de ofício, ou praticá-lo contra disposição expressa de lei, para satisfazer interesse ou sentimento pessoal - e por condescendência criminosa - deixar o funcionário, por indulgência, de responsabilizar subordinado que cometeu infração no exercício do cargo ou, quando lhe falte competência, não levar o fato ao conhecimento da autoridade competente; segundo o decreto-lei acima citada em seus artigos 319 e 320 .

Não podendo o Gestor Público alegar desconhecimento da lei, como de resto nenhum cidadão brasileiro pode alegar tal condição, então é necessário que o mesmo cada vez mais se imbua de conhecimentos da Segurança no Trabalho para que tanto proteja ao trabalhador quanto a si mesmo no cumprimento de suas atribuições. Até para que sendo eficaz sua função gestora seja também eficiente quanto ao cumprimento da legislação vigente.

A seguir se apresenta as principais percepções dos que se auferiu junto aos acadêmicos que se dispuseram a cooperar com o esforço de pesquisa que ora se apresenta.

\section{Percepções dos Acadêmicos do Curso de Tecnologia em Gestão Pública acerca do Segurança no Trabalho}

A percepção de um grupo ou individuo é determinada pelo seu modo de se elucidar cognitivamente a realidade com a qual entra em contato, em conformidade com Moraes (2000) e Moraes (2007).

As percepções, assim, se constituem em um entendimento que necessariamente não se pode universalizar, entretanto podem cooperar com a construção de uma teoria ou compreensão que auxilie a determinar condições de apreensão de significado sobre um evento ou fato.

Sobre a Segurança no trabalho os acadêmicos confluíram em suas percepções para o que segue:

- A Segurança no Trabalho é um dever mais do que legal do Gestor Público, é um imperativo moral e ético daquele a quem vidas humanas se submetem em uma relação hierárquica de comando no mundo do trabalho. 
- O Gestor Público é chamado a dar exemplo social no cumprimento das diretrizes legais para Segurança no trabalho, caso contrário não terá autoridade moral para chamar a sociedade a cumpri-las.

- O Gestor Público, no uso de suas atribuições, não pode ser complacente com o descaso para com a Segurança no Trabalho, pois negligenciá-la equivale a mal gerir por completo a coisa pública.

- O direito de regresso, as penalidades civis e criminais decorrentes de imperícia, imprudência, negligência e omissão quanto à Segurança no Trabalho devem servir com alerta ao Gestor Público para que este cumpra fielmente suas responsabilidades; mas, não devem ser impeditivos para que este se disponha a assumir compromissos e responsabilidade em cargos cada vez maiores dentro do Estado.

- O Gestor Público deve zelar por fazer cumprir a legislação de Segurança no Trabalho por seus colegas servidores como política de gestão de pessoas.

- O Gestor Público, quando responsável pela contratação do serviço de terceiros, deve se assegurar de que organizações que prestem serviços ao Estado cumpram a legislação de Segurança no Trabalho.

- O Gestor Público deve estar atento para as alterações na legislação que diz respeito à Segurança no Trabalho para que se dê fiel cumprimento à mesma.

- A prevenção a acidentes e doenças no trabalho é a essência da Segurança no Trabalho e como tal antecipar riscos é fundamental.

- O servidor sob a égide do Gestor Público deve ser sempre alertado, treinado e informado sobre os determinantes de Segurança no Trabalho e no caso de descumprimento destes misteres ou em sua negligência deve ser advertido, punido ou colocado à disposição da administração pública para demissão.

- As condições em que o ambiente de trabalho se encontram não deve ser desculpa para o Gestor Público negligenciar os ditames da Segurança no Trabalho; antes se deve comunicar aos superiores sobre as circunstâncias para que não se incorra em omissão.

- Caso situações problemáticas quanto à Segurança no Trabalho levadas a superiores não sejam devidamente contempladas, deve se fazer denúncia a autoridades competentes que garantam a saúde e a segurança dos servidores sob sua 
responsabilidade administrativa.

- O Estado ainda não faz uso corriqueiro de seu direito de regresso quando responde por danos causados à saúde do servidor ou em situações de acidente de trabalho pelo qual o servidor passe.

- O Estado não dá a devida importância à saúde e Segurança no Trabalho do servidor e nem a maioria dos gestores públicos com quem os acadêmicos travam ou travaram contato.

\section{Considerações Finais}

Ao se realizar o relato de uma condição particular de universo pesquisado na forma de artigo se busca cooperar com a experiência particular na construção de um entendimento coletivo. Conquanto tenha se feito uso de paradigma científico e de balizas metodológicas sistematizadas e metodologizadas, credita-se as considerações que se seguem como fonte de informações e dados assumidos como verdadeiros para a situação em pauta.

Dá-se relevo à dimensão ética e moral que os acadêmicos apontaram como que concorrendo com a dimensão legal da Segurança do trabalho. A valorização da vida, saúde e segurança do trabalhador como imperativo do Gestor público salta também aos olhos como uma auspiciosa percepção de que os acadêmicos entenderam adequadamente ao espírito da legislação. A vida do trabalhador está acima do trabalho que desempenha, é a dignidade do sujeito que confere valor à sua segurança - o risco e a insegurança do trabalho roubam do sujeito sua natural condição de humanidade e de direito à saúde quando lhe são vilipendiosos.

Ao apontarem o Gestor Público como referência para o Gestor Privado no cumprimento da legislação, indicaram o importante papel que o Gestor Público tem como exemplo social de idoneidade e responsabilidade no que diz respeito ao seu papel de gestor da coisa pública. A mesma condição diz respeito ao repudiarem o descaso, imperícia, omissão, imprudência e negligência ao assunto em foco.

A implicação de responsabilidade civil e criminal sobre acidente do trabalho e doença laboral é vista como sinalizadora para o bom proceder mais do que uma ameaça ao gestor, talvez até porque o Estado não tenha exercido historicamente com afinco os direitos de regresso - depreende-se da fala dos acadêmicos. 
Ressalta-se que se faz uma ligação de responsabilidade na gestão de pessoas independentemente da departamentalização do Estado ou de terceiros por ele contratados e que a Segurança no Trabalho pode se tornar uma estratégia de comprometimento tanto do gestor como do servidor no cumprimento da legislação.

O cumprimento da lei é ressaltado como fundamental no exercício da Gestão Pública e seu cumprimento é apresentado como responsabilidade de todos (servidores, gestores e autoridades).

Causa espécie, contudo, se verificar na fala dos acadêmicos que estes percebam que o Estado não tem valorizado a Segurança do Trabalho, em especial porque a maior parte destes acadêmicos é também servidor público. Tal indicativo pode se tornar fator importante a ser investigado - como pode ser que o Estado que legisla a favor da Segurança do Trabalho não se esmera ele mesmo para que esta se torne real para os que como funcionários públicos atuam? Ainda se poderia perguntar: qual é a razão pela qual o Estado não tem valorizado a Segurança do Trabalho?

Mas, estas são questões que remetem a estudos que não se constituíram no escopo do recorte desta pesquisa. Entretanto, a partir daí podem se tornar justificáveis: da expressão e de percepções de estudantes que são servidores públicos se pode investigar a condição do Estado como tal e da situação da política de Segurança do trabalho que emprega.

Por fim, um estudo mais amplo (com número maior de participantes e de outros cursos que contemplem unidade curricular igual ou semelhante) pode cooperar para que o debate sobre o assunto se torne mais amplo e melhor examinado.

\section{Referências}

ARAUJO, G. M. de. Normas regulamentadoras comentadas. Curitiba: Autores Paranaenses, 2007.

CÓDIGO PENAL BRASILEIRO, Decreto-Lei N. ${ }^{\circ} 2.848$, de 7 de Dezembro de 1940.

CARDELLA, B. Segurança no trabalho e prevenção de acidentes: uma visão holística. São Paulo: Atlas, 1999. 


\section{DIVERS@!}

DEMO, P. Metodologia científica em ciências sociais. 2. ed. São Paulo: Atlas, 1989.

DEMO, P. Pesquisa e informação qualitativa: aportes metodológicos. Campinas: Editora Papirus, 2004.

FRANCO, M. R. Contribuições da incubadora tecnológica da Universidade Federal do Paraná para o desenvolvimento de cooperativas: um estudo de caso. 2001. Dissertação. (Mestrado em Administração) - Universidade Federal do Paraná.

FRANCO, M. Padrões de qualidade de produtos moveleiros: um estudo de caso no Pólo de Arapongas, Paraná. 2008. Tese. (Doutorado em Engenharia Florestal) - Universidade Federal do Paraná.

GIL, A. C. Métodos e técnicas de pesquisa social. 4. ed. São Paulo: Atlas, 1994.

GODOY, A. S. Introdução à pesquisa qualitativa e suas possibilidades. RAE, São Paulo, v. $35, n^{\circ} 2$, p. $57-63$, março/abril. 1995.

GONÇALVES, E. A. Manual de segurança e saúde no trabalho. 2. ed. São Paulo: ITR, 2003.

HOEPPNER, M. G. Normas regulamentadoras relativas á segurança e medicina do trabalho. 3. ed. São Paulo: Ícone Editora Ltda., 2007.

KAWAMOTO, E. E. Acidentes: como socorrer e prevenir. São Paulo: EPU, 2002.

LAKATOS, Eva M. e MARCONI, M. de A. Fundamentos de metodologia científica. 3. ed. São Paulo: Atlas, 1991.

MORAES, P. E. S. Estratégia de pesquisa sobre gestão da qualidade e da inovação tecnológica: o caso de serrarias do pólo madeireiro de Telêmaco Borba, Paraná. 2007. Tese (Doutorado em Engenharia Florestal) - Universidade Federal do Paraná. 


\section{DIVERS@!}

MORAES, P. E. S. Um espaço comunicativo entre a tecnologia ambiental, a engenharia química e a educação tecnológica. 2000. Dissertação. (Mestrado em Tecnologia). Universidade Tecnológica Federal do Paraná.

MORAES, P. E. S. Metodologia da pesquisa. Curitiba: IBRATE, 2002.

MOSER, A. Introdução à Filosofia e Teoria do Conhecimento. Jandaia do Sul: FAFIJAN, 2000.

POPPER, K. R. Conhecimento objetivo: uma abordagem evolucionária. Belo Horizonte: Itatiaia; São Paulo: EDUSP, 1975.

RICHARDSON, R. J. et alli. Pesquisa social: métodos e técnicas. São Paulo: Atlas, 1989.

TISKI, S. Sobre a questão da ontologia em Merleau-Ponty. In: Boletim - Revista da área de Humanas. Londrina: Universidade Estadual de Londrina, N 51, Julho/ Dezembro de 2006.

WACHOWICZ, M. C. Segurança, saúde e ergonomia. Curitiba: IBPEX, 2007.

ZOCCHIO, A. Prática de prevenção de acidentes: $A B C$ da segurança no trabalho. São Paulo: Atlas, 2002. 